This item was submitted to Loughborough's Research Repository by the author.

Items in Figshare are protected by copyright, with all rights reserved, unless otherwise indicated.

\title{
News implied volatility and the stock-bond nexus: Evidence from historical data for the USA and the UK markets
}

PLEASE CITE THE PUBLISHED VERSION

https://doi.org/10.1016/j.mulfin.2018.08.001

PUBLISHER

(C) Elsevier

VERSION

AM (Accepted Manuscript)

\section{PUBLISHER STATEMENT}

This paper was accepted for publication in the journal Journal of Multinational Financial Management and the definitive published version is available at https://doi.org/10.1016/j.mulfin.2018.08.001

\section{LICENCE}

CC BY-NC-ND 4.0

\section{REPOSITORY RECORD}

Gupta, Rangan, Christos Kollias, Stephanos Papadamou, and Mark Wohar. 2018. "News Implied Volatility and the Stock-bond Nexus: Evidence from Historical Data for the USA and the UK Markets". figshare.

https://hdl.handle.net/2134/35697. 


\title{
NEWS IMPLIED VOLATILITY AND THE STOCK-BOND NEXUS: EVIDENCE FROM HiSTORICAL DATA FOR THE USA AND THE UK MARKETS ${ }^{\#}$
}

\begin{abstract}
:
Using monthly stock and bond returns data from both the USA and the UK, this study addresses the issue of whether news implied volatility and its main components have affected in any significant manner the time-varying stock-bond covariance, their returns and their variances. The time varying association between the two markets has attracted considerable attention due to its important implications for asset allocation, portfolio selection and risk management. The issue at hand is addressed using a VAR(p)-BEKK-GARCH(1,1)-in-mean model and the results reported herein indicate that different types of news implied volatility as quantified by the NVIX developed by Manela and Moreira (2017) affects differently USA and UK returns, variances and covariance.
\end{abstract}

JEL classification: E44, G10, G15

Keywords: NVIX index; Stock-bond covariance; GARCH models

\# We would like to thank the Editor, Professor Peter G. Szilagyi, and two anonymous referees for many helpful comments. However, any remaining errors are solely ours. 


\section{INTRODUCTION}

Stocks and bonds constitute the two major classes of assets traded on capital markets. Because of their different risk-return characteristics, they are the main building blocks of most investment portfolios. The time varying association between stock and bond markets has important implications for asset allocation, portfolio selection and risk management. Hence, not surprisingly, it is a theme that has attracted extensive attention and has featured in a steadily expanding body of literature (inter alia: Aslanidis and Christiansen, 2012; 2014; Baele et al. 2010; Skintzi, 2017; Ohmi and Okimoto, 2016; Andersson et al. 2008; Hassan et al. 2017; Baur and Lucey, 2009; Connolly et al. 2007; Rankin and Shah Idil 2014; Sakemoto, 2018).

Several economic factors act as driving variables of this dynamic intertemporal relation between the two assets. In broad terms, given that both markets are influenced by common macroeconomic factors such as for instance inflation expectations or expected economic growth, the association between bond and stock returns is expected to be positive during periods of macroeconomic stability (inter alia: Shiller and Beltratti, 1992; Campbell and Ammer, 1993; Asgharian et al. 2015; Macchiarelli, 2014; Ilmanen, 2003; Connolly et al. 2005; Dimic et al. 2016; Dajcman, 2012; Kim et al. 2006). However, as has been shown, a negative stock-bond association can also be the case. This negative association is induced by the flight-to-quality phenomenon. In times of stock market turbulence, investors invariably become more risk averse. As a result, they tend to adjust their portfolios switching from risky assets such as stocks to safer assets such as long-term government bonds, thus causing a stock-bond decoupling (inter alia: d'Addona and 
Kind, 2006; Chang and Hsueh, 2013; Durand et al. 2010; Yang et al. 2009, 2010; Baur and Lucey 2009; Gulko, 2002; Thomadakis, 2012). Reported empirical evidence indicates that during periods characterized by market uncertainty and hence high volatility, a flight-to-quality effect can be triggered-off with investors fleeing from stocks to bonds since the latter, as already pointed out, are almost invariably considered to be a more secure and less risky investment. Similarly, reported findings indicate that the reverse flow between the two markets, i.e. a flight-from-quality, takes place once uncertainty subsides. Both of these flows bring about a negative effect on the stockbond covariance and hence result in a decrease in the covariance coefficient (Jammazi et al. 2015; Kollias et al. 2013).

Apart from the usual cohort of economic factors that can affect the relationship between the two markets over the long run, exogenous events can also exert an impact on the covariance between bonds and stocks over the short run. A growing number of empirical studies has shown that markets and market agents react to exogenous events. Such exogenous events include natural or anthropogenic catastrophes, civil strife and social unrest, political upheavals, armed interstate or intrastate conflict, insurgencies as well as other violent one-off incidents such as a terrorist attack (inter alia: Schneider and Troeger 2006; Apergis et al. 2017; Guidolin and La Ferrara 2010; Nikkinnen et al. 2008). Although the probability of their occurrence is omnipresent, events like these are invariably unanticipated. Hence, as observed by Kollias et al. (2013), they have the potential to generate uncertainty. As a result, risk perceptions are adversely influenced, given that such events can and do exert a negative effect on investors' sentiment and their concomitant assessment of markets and market risk. It follows that markets' volatility and portfolio allocation decisions are influenced, including the stock-bond association by flights-to-quality induced by such exogenous events (inter alia: Brune et al. 2015; Aslam and Kang, 2015; Kaplanski and Levy 
2010; Kollias et al. 2013). Furthermore, media coverage of a particular event may multiply an initial reaction in the financial market. Fang and Peress (2009) indicate that companies without media coverage have different returns from companies with high media coverage. Over the past decade or so, a series of studies (Tetlock, 2007; Tetlock et al. 2008; Dougal et al.2012; Boudoukh et al. 2013; Chen et al. 2014) indicate that news stories often contain useful information related to predicting both earnings and stock returns on aggregate and individual levels. For instance, according to Del Giudice- Paltrinieri (2017), mutual fund flows were affected by retail investors' behavior and their overreaction to the Ebola outbreak and the Arab Spring events. Retail investors overreacted to these major events, withdrawing their savings from African mutual funds. However, what is interesting is that the withdraw is stronger when connected to the media coverage of these events: the higher the number of articles on the Arab Spring and Ebola, the higher the withdrawals.

In the broader spirit of such studies, this paper takes up the effect exerted on the stock-bond relationship by uncertainty inducing news. In particular, we use the recently published news implied volatility index (NVIX) of Manela and Moreira (2017) to examine how the nexus between the two markets is affected by news and the concomitant uncertainty they potentially cause. The advantage associated with the Manela and Moreira (2017) NVIX dataset is its forward-looking nature, leaving space for testing its predictability (a) on returns, (b) on variances and (c) on covariances of the stock and bond markets. Moreover, the fact that it spans many decades and it allows for long-term based analysis and inferences. The point that it is also decomposed into different news sources and events adds further value to the use of this index since different kinds of news can bring about different kinds of effects on the nexus between the two markets. Moreover, the response to news-based implied volatility index (NVIX), and not the VIX itself may affect significantly investors' reactions in stock and bond markets, and consequently the dynamic 
correlation between the two markets. The usefulness of this index on commodity markets has recently attracted attention in the relevant literature (Antonakakis et al. 2014). For instance, according to Su et al. (2018) the oil supply and aggregate demand shocks usually play a leading role on relatively long-term NVIX, while the oil specific demand shocks are sensitive to the fluctuations of NVIX. Liu et al. (2018) show that NVIX exerts a positively significant influence on volatilities of non-energy futures, while it does not affect volatilities of energy futures. Worth mentioning the stock market uncertainty component of NVIX significantly affects both energy and non-energy futures.

To the best of our knowledge, the question of how NVIX and its main components affect the stock-bond covariance has not been addressed before. We do so here employing a multivariate Generalised Autoregressive Conditional Heteroskedasticity (GARCH) framework ${ }^{1}$. We use the unrestricted Vector Autoregressive - GARCH model in the empirical investigation that follows for two main reasons. First, as pointed out by Kollias et al. (2013), the VAR representation allows the identification of the causality direction between stock and bond market returns. It does so without explicitly assuming a specific direction. Second, heteroskedastic returns are a common characteristic in stock and bond markets disturbing the validity of the estimated parameters. It is for this reason, that modelling time-varying conditional variances and covariance is widely regarded as the most suitable and appropriate approach in such cases. In the section that follows, the data and methodology are presented. Section three reports and discusses the findings while section four concludes the paper.

\footnotetext{
${ }^{1}$ Multivariate GARCH models have been widely used to study covariance (Longin and Solnik 1995; Kim et al. 2006; Li and Zhou 2008; Bonga-Bonga, 2017).
} 


\section{DATA ANd Methodology}

The financial data set used in our empirical estimations, consists of monthly data on American and British bond and stock returns. They are two of the largest and most important economies worldwide with large and mature bond and stock markets. As shown by Penga et al. (2018), in a time varying correlation window the US stock market presents the higher correlation with the UK one among the G7 countries. Hence, it is worth investigating examining whether the NVIX has different effects in these two mature markets with significant trading activity and high correlation. These two markets present a rich database extending back to 1892 (from July 1892 to March 2016) in US case, and back to 1933 (January 1933 to March 2016) in British case. The US stock log returns are calculated from the S\&P500 total return index and the British returns from the FTSE All Share total return index, with returns being computed as the first-differences of the natural logs of these indices. The bond log returns for USA and Britain are extracted from the 10year government bond total return indices, with data for stocks and bond prices being recovered from the Global Financial Database.

The data on the news-based implied volatility index (NVIX) and its main components are drawn from Manela and Moreira (2017) ${ }^{2}$. The latter, produced a news-based measure of uncertainty derived from the co-movement between the front-page (title and abstract) articles of the Wall Street Journal and options implied volatility (VIX). Manela and Moreira (2017) focus on

\footnotetext{
${ }^{2}$ The data are available at: http://apps.olin.wustl.edu/faculty/manela/mm/nvix/nvix interactive.html.
} 
front-page titles and abstracts in order to ensure feasibility of data collection, and also because these are manually edited and corrected following optical character recognition, which in turn, improves their earlier sample reliability. The NVIX data is found to peak during stock market crashes, times of policy-related uncertainty, world wars and financial crises. Given its forwardlooking nature, another significant characteristic of this index is its increased stock market predictability and its rise before transitions into economic sharp downturns. Moreover, the comparative advantage of the index stems from the fact that it is decomposed into different news sources and events that can affect differently the association between the two stock and bond markets. In particular, the NVIX constituent components allow from uncertainty stemming from government policy (henceforth GOV), security markets uncertainty (SecMkts), uncertainty associated with war and conflict (War), natural disaster associated uncertainty (NATDIS), intermediation uncertainty (INTERMED) and finally unclassified uncertainty (Unclass). Intuitively, each of the sub-indices is expected to exert different effects on the stock-bond mean returns, conditional variance and co-variance between the two markets for the USA and the UK respectively. The start and the end of our analysis is purely driven by the availability of continuous data for the overall NVIX and its components. Note that, even though the NVIX data starts from July 1889, it has missing data between January 1892 to June 1892; hence, we start our analysis from July 1892, even though data for the US economy is available from November 1790.

Figure 1, offers a graphical representation of the NVIX and its six constituent components. As can be observed, each of the indices exhibits an appreciably different pattern and variability. In order to examine the impact of the uncertainty based on news, on the stock-bond covariance, their returns and their variances, the NVIX variable and its components are introduced in both VAR model and multivariate GARCH analysis that follows. In order to allow for the time issue 
associated given that these indices presents uncertainty over the next month, we introduce the uncertainty indices lagged, at time $t-1$.

Figure 1: Graphical representation of the composite NVIX and its main components

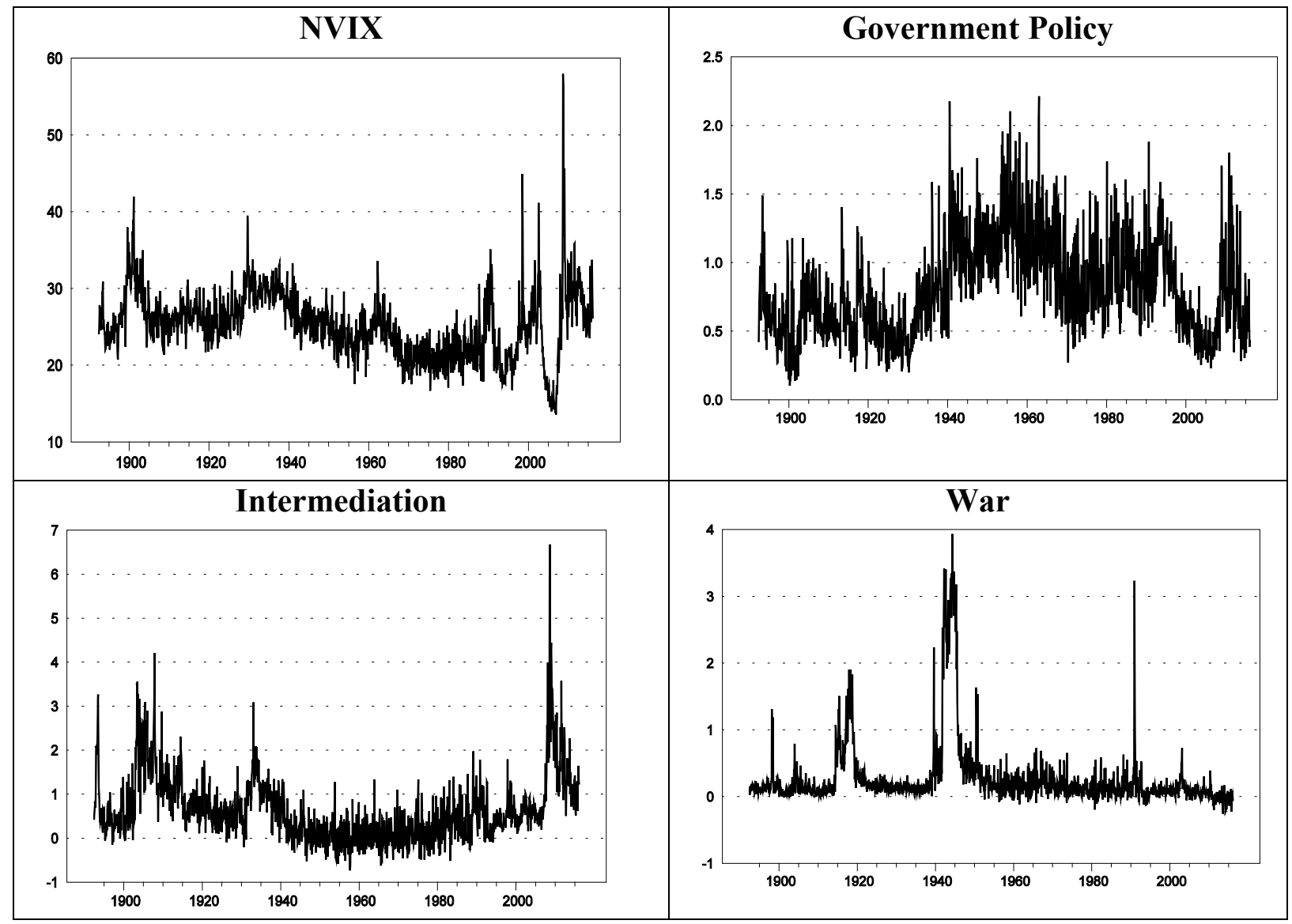




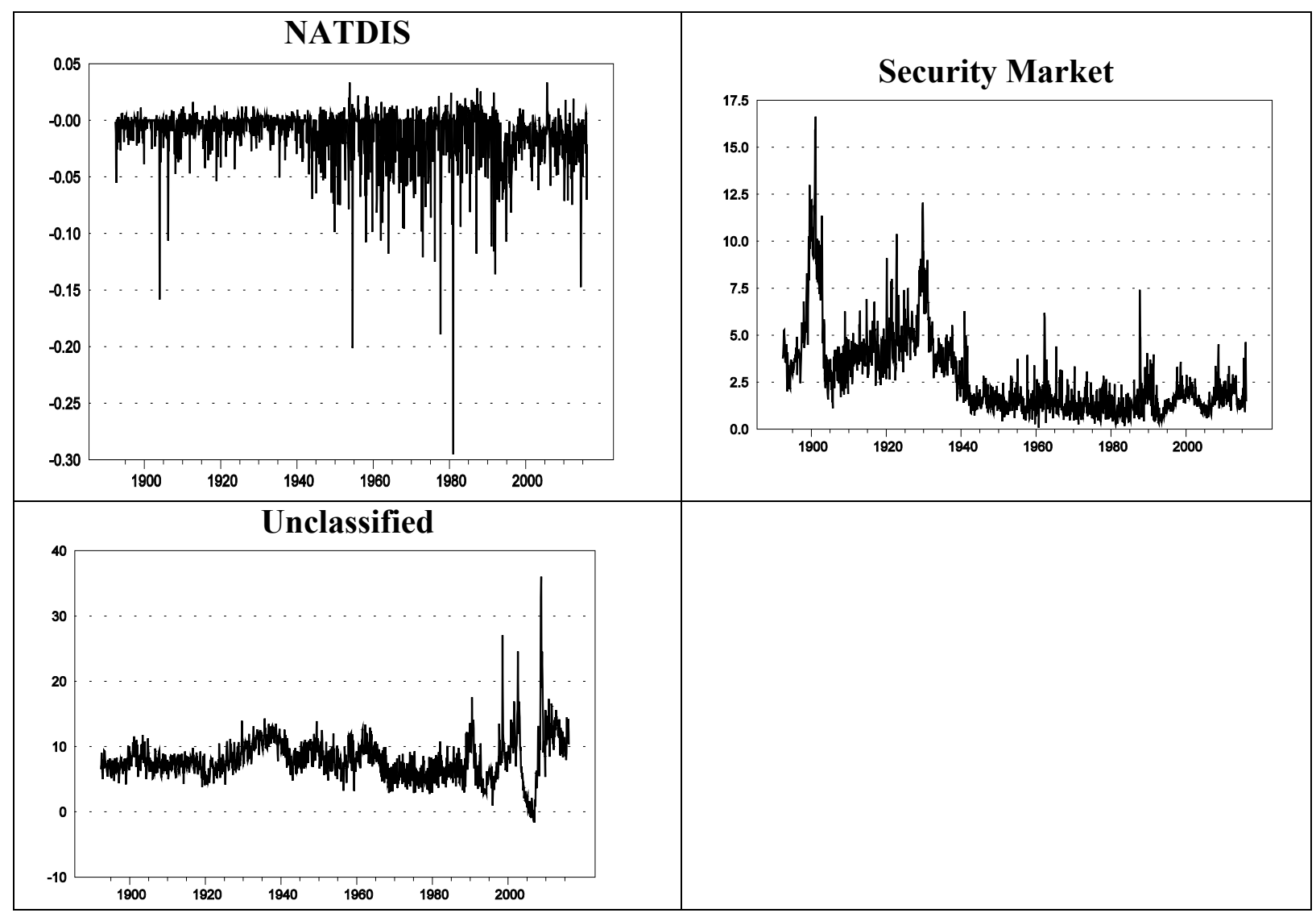

As previously noted, the nexus between the two markets is examined through the use of a multivariate GARCH framework that allows us to estimate time varying variances and covariance in both stock and bond market. The $V E C H^{3}$, the diagonal $V E C H$ and the $B E K K$ (Baba, Engle, Kraft and Kroner) ${ }^{4}$ models ${ }^{5}$ are among the several multivariate GARCH formulations that have been proposed and used in the relevant literature. For the purposes of our empirical investigation, the bivariate unrestricted BEKK-GARCH(1,1) model as proposed by Engle and Kroner (1995) is used

\footnotetext{
${ }^{3}$ Its name is taken by the vectorized representation of the model. Where $\mathrm{VECH}($ ) denotes the operator that stacks the lower triangular portion of a symmetric $\mathrm{N} \times \mathrm{N}$ matrix into an $\mathrm{N}(\mathrm{N}+1) / 2 \times 1$ vector of the corresponding unique elements. ${ }^{4}$ The BEKK acronym refers to a specific parameteriztion of the multivariate GARCH model developed by Engle and Kroner (1995).

${ }^{5}$ For a more detailed discussion and survey see among others Bauwens et al. (2006)
} 
in order to probe into the effects exerted by news implied uncertainty on the stock-bond association in the case of the USA and UK markets. ${ }^{6}$.

The BEKK-GARCH model captures efficiently one important feature that an MGARCH model should have, it should be flexible enough to state the dynamics of the conditional variances and covariances (see for instance Bauwens et al. 2006). It allows to identify direct effects from one market to the other in both variances and covariances equations in one-step estimation. On the other hand, other models, like the DCC-GARCH model contributes to the parsimony of the specification by simplifying the model estimation. However, this parsimony may reduce the number of parameters, in which situation the relevant dynamics in the covariance matrix cannot be captured.

Nevertheless, in broad terms, the bivariate version of the general BEKK $(p, q)$ model with $\mathrm{p}=\mathrm{q}=1$ represents a good compromise between conducting a multivariate analysis and still achieving robust convergence. In addition, the BEKK model by Engle and Kroner (1995) adequately addresses the difficulty associated with $V E C H$, ensuring that the conditional variancecovariance matrix is always positive definite. The joint process governing the two variables in question is modeled with the bivariate Vector Autoregressive (VAR) unrestricted BEKKGARCH(1,1)-in-mean model. The news implied uncertainty variable, as encapsulated by NVIX and its components, is included each time in the construction of the mean, variances and covariance matrices. Equation (1) depicts the expression for the conditional mean.

$$
\mathbf{x}_{\mathbf{t}}=\gamma+\boldsymbol{\delta} \sum_{j=1}^{p} \mathbf{x}_{\mathrm{t}-1}+\lambda y_{\mathrm{t}-1}+\zeta \mathbf{h}_{\mathbf{t}}+\boldsymbol{\varepsilon}_{\mathrm{t}}
$$

\footnotetext{
${ }^{6}$ The use of MIDAS-GARCH-DCC (Conrad, et al. 2014) as an alternative methodology that allows us to combine high frequency asset returns with low frequency data (like the NVIX here) is useful in cases when daily asset returns are used. However, in our case this is not possible since only monthly asset returns are available from 1892.
} 
where vector $\mathbf{x}=(R B, R S)$ includes the returns of the bond (RB) and stock (RS) markets, respectively, for each of the two countries examined herein. In each case, the lag length, defined as " $p$ " is based on the Akaike (AIC) criterion. Variable $y$ includes the NVIX index or its constituent component in each model version based on decomposition and classification offered by Manela and Moreira (2017). The $y$ is an exogenous variable presented in both equations ${ }^{7} . \mathbf{h}=\left(h_{11}, h_{22}, h_{21}\right)$ is the GARCH-in-mean vector. The residual vector $\boldsymbol{\varepsilon}=\left(\varepsilon_{1}, \varepsilon_{2}\right)$ is bivariate and student $t$ distributed with $\boldsymbol{\varepsilon}_{t} \mid \Phi_{t-1} \sim T\left(0, \mathbf{H}_{t}\right)$ and the corresponding conditional variance covariance matrix given by:

$$
\mathbf{H}_{\mathbf{t}}=\left[\begin{array}{l}
h_{11 t} h_{12 t} \\
h_{21 t} h_{22 t}
\end{array}\right] \text {. }
$$

The second moment will take the following form:

$$
\mathbf{H}_{\mathbf{t}}=\mathbf{C}_{\mathbf{0}} \mathbf{C}_{\mathbf{0}}^{\prime}+\mathbf{A}^{\prime} \boldsymbol{\varepsilon}_{\mathbf{t}-1} \boldsymbol{\varepsilon}_{\mathbf{t}-1}^{\prime} \mathbf{A}+\mathbf{B}^{\prime} \mathbf{H}_{\mathbf{t}-1} \mathbf{B}+\mathbf{K} \bullet y_{t-1}
$$

where the conditional variance-covariance matrix depends on its past values and on past values of error terms defined in matrix $\boldsymbol{\varepsilon}_{t-1} . C_{0}$ is a $2 \times 2$ matrix, the elements of which are zero above the main diagonal; and $\mathbf{A}, \mathbf{B}$ are $2 \times 2$ matrices. $\mathbf{K}$, is the coefficient matrix for the NVIX or its components indices respectively, and the operator "•" is the element-by-element (Hadamard) product. More analytically:

$$
\mathbf{H}_{\mathbf{t}}=\left(\begin{array}{ll}
c_{11} & 0 \\
c_{21} & c_{22}
\end{array}\right)\left(\begin{array}{ll}
c_{11} & 0 \\
c_{21} & c_{22}
\end{array}\right)^{\prime}+\left(\begin{array}{ll}
\alpha_{11} & \alpha_{12} \\
\alpha_{21} & \alpha_{22}
\end{array}\right)^{\prime} \boldsymbol{\varepsilon}_{t-1} \mathbf{\varepsilon}_{t-1}^{\prime}\left(\begin{array}{ll}
\alpha_{11} & \alpha_{12} \\
\alpha_{21} & \alpha_{22}
\end{array}\right)+\left(\begin{array}{ll}
\beta_{11} & \beta_{12} \\
\beta_{21} & \beta_{22}
\end{array}\right)^{\prime} \mathbf{H}_{\mathbf{t}-1}\left(\begin{array}{ll}
\beta_{11} & \beta_{12} \\
\beta_{21} & \beta_{22}
\end{array}\right)+\left(\begin{array}{ll}
k_{11} & \mathrm{k}_{12} \\
0 & \mathrm{k}_{22}
\end{array}\right) \cdot y_{t-1}
$$

main advantage of the BEKK-GARCH vis-a-vis the VECH-GARCH model is that it guarantees

\footnotetext{
${ }^{7}$ Preliminary Granger causality tests between NVIX and stock-bond returns do present a univariate direction from the former to the later. For reasons of brevity, the results are not presented here but are available upon request.
} 
by construction that the covariance matrices in the system are positive definite. The positive definiteness of the covariance matrix is ensured owing to the quadratic nature of the terms on the equation's (2) right hand sight.

The maximum likelihood is used to jointly estimate the parameters of the mean and the variance equations. In a single equation format, the model may be written as follows:

$$
\begin{aligned}
h_{11, t} & =c_{11}^{2}+\alpha_{11}^{2} \varepsilon_{1, t-1}^{2}+2 \alpha_{11} \alpha_{21} \varepsilon_{1, t-1} \varepsilon_{2, t-1}+\alpha_{21}^{2} \varepsilon_{2, t-1}^{2}+\beta_{11}^{2} h_{11, t-1}+2 \beta_{11} \beta_{21} h_{12, t-1}+\beta_{21}^{2} h_{22, t-1} \\
& +\kappa_{11} y_{t-1} \\
h_{12, t}= & c_{11} c_{21}+\alpha_{11} \alpha_{12} \varepsilon_{1, t-1}^{2}+\left(\alpha_{21} \alpha_{12}+\alpha_{11} \alpha_{22}\right) \varepsilon_{1, t-1} \varepsilon_{2, t-1}+\alpha_{21} \alpha_{22} \varepsilon_{2, t-1}^{2}+\beta_{11} \beta_{12} h_{11, t-1} \\
& +\left(\beta_{21} \beta_{12}+\beta_{11} \beta_{22}\right) h_{12, t-1}+\beta_{21} \beta_{22} h_{22, t-1}+\kappa_{12} y_{t-1} \\
h_{22, t} & =c_{21}^{2}+c_{22}^{2}+\alpha_{12}^{2} \varepsilon_{1, t-1}^{2}+2 \alpha_{12} \alpha_{22} \varepsilon_{1, t-1} \varepsilon_{2, t-1}+\alpha_{22}^{2} \varepsilon_{2, t-1}^{2}+\beta_{12}^{2} h_{11, t-1}+2 \beta_{12} \beta_{22} h_{12, t-1}+\beta_{22}^{2} h_{22, t-1} \\
& +\kappa_{22} y_{t-1}
\end{aligned}
$$

Therefore, the main research hypotheses in our case can be formulated as follows:

$H_{0}^{A}$ : NVIX does not predict stock returns, $\lambda=0$

$H_{0}^{B}$ : NVIX does not predict bond market conditional volatility, $\mathrm{k}_{11}=0$

$H_{0}^{C}$ : NVIX does not predict stock market conditional volatility, $\mathrm{k}_{22}=0$

$H_{0}^{D}$ : NVIX does not predict stock-bond conditional covariance, $\mathrm{k}_{12}=0$

\section{THE FINDINGS}

We start the presentation of the findings with the descriptive statistics for the return series in both the stock and bond markets in each of the two countries examined here. These are shown in Table 1. As it can be seen, the stock and bond mean monthly returns are positive, statistically 
significant and, on the basis of the ADF tests statistic, are characterized as $I(0)$ processes. As one would have intuitively expected, the bond market volatility is lower when compared to corresponding volatility of the stock market. In broad terms, the Jarque-Bera values are high and statistically significant. In the bond markets the degree of skewness measured in absolute terms is higher compared to the corresponding in the stock markets. The Ljung-Box statistics on level returns present evidence for auto covariances in all cases. Moreover, this statistic on squared returns indicates evidence for time varying variability of returns.

Table 1 Descriptive Statistics of Bond and Stock Returns

\begin{tabular}{lrrrr}
\hline \hline & $\begin{array}{r}\text { US Bond } \\
\text { Return }\end{array}$ & $\begin{array}{r}\text { US Stock } \\
\text { Return }\end{array}$ & $\begin{array}{r}\text { UK } \\
\text { Bond } \\
\text { Return }\end{array}$ & $\begin{array}{r}\text { UK } \\
\text { Stock } \\
\text { Return }\end{array}$ \\
\hline Mean & 0.393 & 0.397 & 0.558 & 0.499 \\
Median & 0.297 & 0.752 & 0.385 & 0.928 \\
Maximum & 11.945 & 40.746 & 8.019 & 42.319 \\
Minimum & -8.243 & -30.753 & -5.109 & -30.924 \\
Std. Dev. & 1.643 & 4.238 & 1.329 & 4.857 \\
Skewness & 0.604 & -0.463 & 0.831 & -0.155 \\
Kurtosis & 8.629 & 14.146 & 7.503 & 11.722 \\
& & & & \\
ADF t-statistic & $-20.9^{* * *}$ & $-28.4^{* * *}$ & $-27.7 * * *$ & $-24.9 * * *$ \\
J-B test & $2050.6^{* * *}$ & $7739.7 * * *$ & $958.8^{* * *}$ & $3170.8^{* * *}$ \\
Q(12) & $48.54^{* * *}$ & $137.3^{* * *}$ & $93.60^{* * *}$ & $28.08^{* * *}$ \\
Qsq(12) & $565.7 * * *$ & $417.9^{* * *}$ & $398.1 * * *$ & $147.4 * * *$ \\
& & & & \\
\# Obs. & 1485 & 1485 & 999 & 999 \\
\hline \hline Mean, Median, Maxime
\end{tabular}

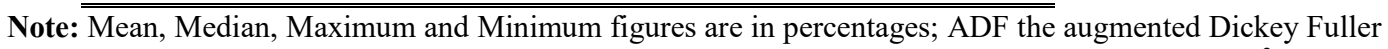
test; J-B the Jarque-Bera Test provides evidence against normally distributed returns; Q(12) and $Q^{2}(12)$ are the Ljung-Box statistic based on the returns and the squared returns respectively up to the $12^{\text {th }}$ order.

Figures 2 and 3 also provide evidence for time varying variances for bond and stock returns in both countries. Noteworthy is that since the mid-70s the bond variability seems to have increased significantly. This is true both in the case of the US bond market (Figure 2) as well as the UK one (Figure 3). Furthermore, the distribution of these is fat-tailed because, as can be seen, excess kurtosis is greater than zero. These results are more pronounced on stock compared to bond returns. 
In view of this, adopting the $\operatorname{VAR}(\mathrm{p})$-BEKK-GARCH(1,1)-in-mean model in our analysis emerges as an appropriate choice in order to take into account all of the above mentioned data characteristics and the well-known risk-return relationship in finance literature. According to most models used in finance there is a positive relationship between risk and return. The investors should be rewarded on their risk taken in their investment decisions. This main finance principle can be covered by the ARCH-M model, firstly suggested by Engle, Lillien and Robins (1987). In the GARCH-M model the conditional variance of asset returns is directly related to asset returns since it enters into the conditional mean equation.

Figure 2: US Bond and Stock Monthly Returns

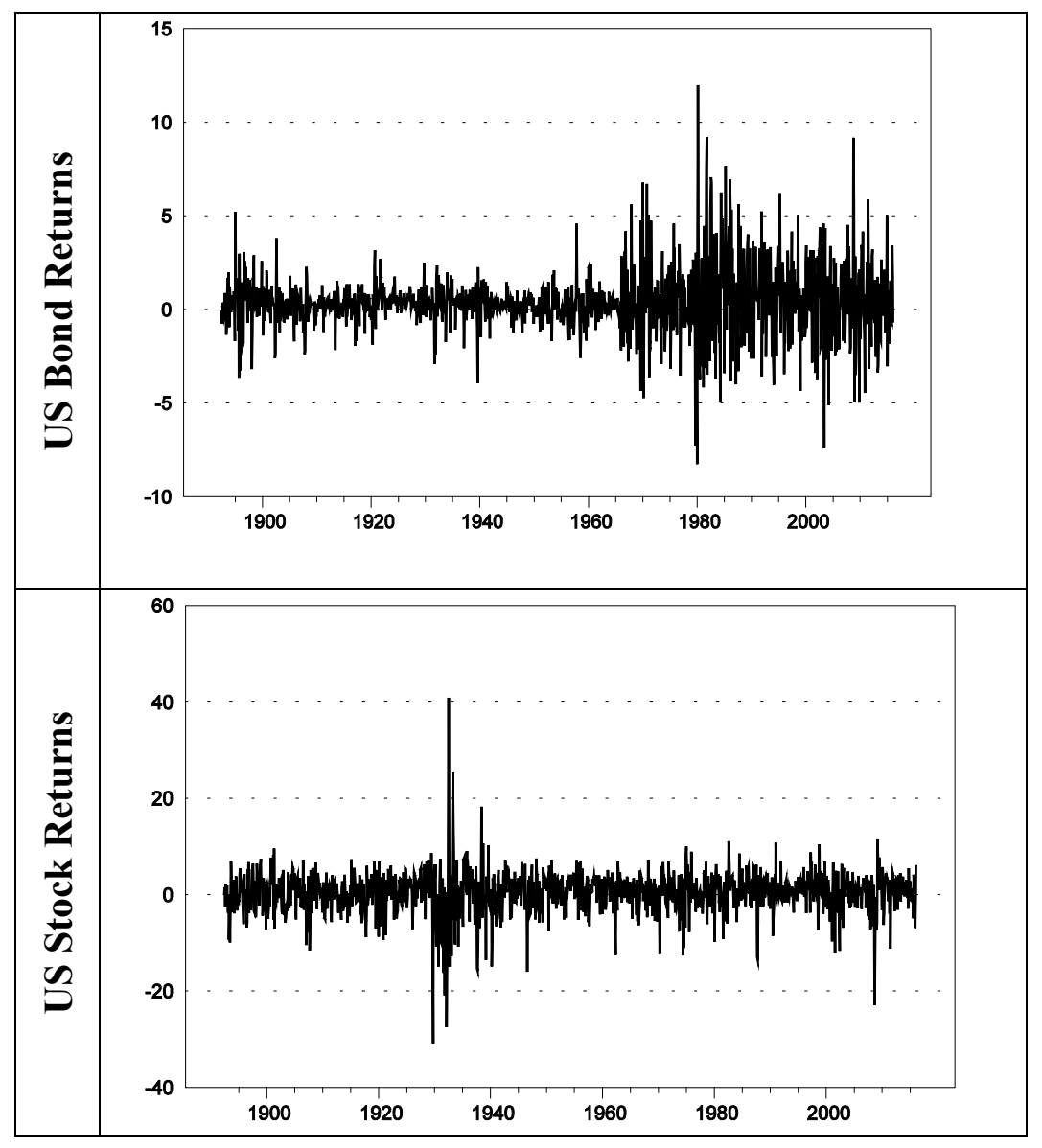


Figure 3: UK Bond and Stock Monthly Returns

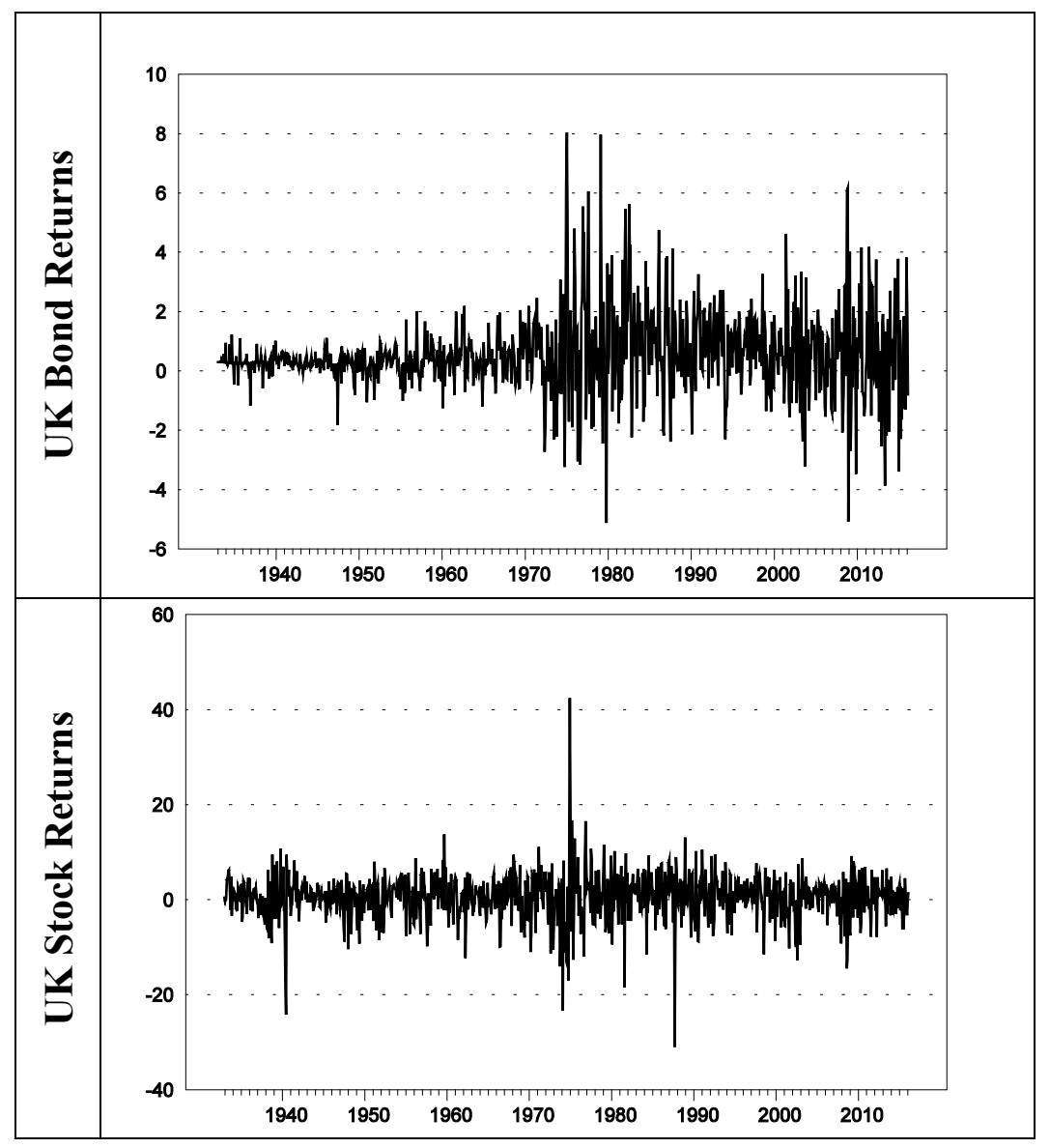

The estimation results for the VAR-unrestricted BEKK-GARCH(1,1)-in-mean model are shown in Table 3 for the US bond and stock markets and in Table 4 for the UK ones. The upper part of the tables presents the estimated coefficients and their statistical significance while the lower part the diagnostic tests applied on the residuals are shown. We assume the return residuals follow a bivariate student $t$ density and the relevant $t$-distribution parameter is presented in this lower part of Tables 3 and 4. Based on the diagnostic tests the problems of autocorrelations and heteroscedasticity previously presented in Table 1 concerning the series of interest have been resolved following the proposed modelling. In the cases where such problems persist the Newey and West (1987) standard errors are calculated in order to ensure that reliable inferences are made. 
Table 2: Summary of results

\begin{tabular}{|c|c|c|c|c|c|c|c|}
\hline \multicolumn{8}{|c|}{ USA } \\
\hline & NVIX & GOV & INTERMED & NATDIS & SecMkts & War & Unclass \\
\hline $\begin{array}{l}\text { Bond market } \\
\text { Returns }\end{array}$ & & - & & & + & & \\
\hline $\begin{array}{l}\text { Stock market } \\
\text { Returns }\end{array}$ & & & - & & & + & \\
\hline $\begin{array}{l}\text { Bond market } \\
\text { Volatility }\end{array}$ & - & & & & & & - \\
\hline $\begin{array}{l}\text { Stock market } \\
\text { Volatility }\end{array}$ & + & & & + & & & + \\
\hline Covariance & & & + & & + & & \\
\hline \multicolumn{8}{|c|}{ UK } \\
\hline & NVIX & GOV & INTERMED & NATDIS & SecMkts & War & Unclass \\
\hline \multicolumn{8}{|l|}{$\begin{array}{l}\text { Bond market } \\
\text { Returns }\end{array}$} \\
\hline $\begin{array}{l}\text { Stock market } \\
\text { Returns }\end{array}$ & & & & & - & & - \\
\hline $\begin{array}{l}\text { Bond market } \\
\text { Volatility }\end{array}$ & - & & + & + & & & - \\
\hline $\begin{array}{l}\text { Stock market } \\
\text { Volatility }\end{array}$ & & & + & + & & & \\
\hline Covariance & + & & & + & & - & + \\
\hline
\end{tabular}

We start with a bird's eye view summary of the results presented in Table 2 before we move to a more detailed presentation and discussion. As can be seen, from the two bond markets, only the US market returns are positively affected by uncertainty news concerning the corresponding security markets. Stock market returns respond positively to war news uncertainty and negatively on INTERMED news in USA. In UK, stock returns are mainly reduced after 
implied uncertainty from security market news and uncertainty from unclassified news. Bond market volatility is reduced significantly based on NVIX and unclassified news both in the US and the UK. Stock market volatilities in both cases are affected positively due to NATDIS news. However, in the case of US unclassified news adds to stock market volatility while in UK case a similar effect is brought about by INTERMED news. Finally, covariance between stock and bond market is usually increased due to uncertainty news. However, different types of news are responsible for this increase between stock and bond markets, across the two countries. Only in the case of the UK the bond and stock market are negatively correlated in cases of War news uncertainty.

We now turn to a more detailed presentation and discussion of the results yielded from estimating the mean equation for the US bond and stock returns. The well-known risk-return result is shown, according to which investors require high return for the risk undertaken. This is present only in the bond market but not in the stock market (see Table 3). In particular, bond volatility coexists with high bond returns and this result does not appear to be affected when different components of NVIX are used in the bond equation as can be deduced from coefficients $H(1,1)$. Stock market conditional volatility does not affect bond returns as indicated by coefficients $\mathrm{H}(2,2)$ while the covariance of the two markets contributes positively to bond returns according to NVIX as shown by coefficients $H(1,2)$. This is the case with all the uncertainty news components of NVIX with the exception of uncertainty news associated with government policy (GOV) and security markets (SecMkts) as can be observed in the relevant columns of Table 3. Generally speaking, bond returns present first order autocorrelation in most of the times, while stock market is characterised by a higher order of autocorrelation (see coefficients of lagged bond and stock returns). Stock returns are positively affected by bond returns with one and five time lags while 
the opposite is not the case. This implies a unidirectional relationship from bond market to stock market.

Table 3: Estimation results for the VAR-BEKK-GARCH(1,1)-in-mean model for US data 


\begin{tabular}{|c|c|c|c|c|c|c|c|c|c|c|c|c|c|c|c|}
\hline & & Exogenous & $s \mathrm{NVIX}_{\mathrm{t}-1}$ & Exogenou & Is $\mathrm{GOV}_{\mathrm{t}-1}$ & Exogenou & Is INTERMED I $-1_{1}$ & Exogenou & s NATDIS $_{\text {t-1 }}$ & Exogenou & SecMkts t $-1_{1}$ & Exogenou & us War ${ }_{t-1}$ & Exogenou & s Unclass $_{t-1}$ \\
\hline & & $\mathrm{R}_{\text {Bonds }}-\mathrm{R}$ & $\mathrm{R}_{\text {Stocks }}$ & $\mathrm{R}_{\text {Bonds }}-\mathrm{R}$ & $\mathbf{R}_{\text {Stocks }}$ & $\mathbf{R}_{\mathrm{Bor}}$ & ${ }_{\mathrm{nds}}-\boldsymbol{R}_{\text {Stocks }}$ & $\begin{array}{r}\mathbf{R}_{\text {Bonds }} \\
\end{array}$ & $-R_{\text {Stocks }}$ & $\mathbf{R}_{\text {Bonds }}$ & $-R_{\text {Stocks }}$ & $\mathrm{R}_{\text {Bonds }}-\mathrm{R}$ & $R_{\text {Stocks }}$ & $\mathbf{R}_{\text {Bonds }}$ & $-R_{\text {Stocks }}$ \\
\hline & Variable & Coeff & $\begin{array}{l}\text { T-Stat. } \\
p \text {-value }\end{array}$ & Coeff & $\begin{array}{l}\text { T-Stat. } \\
p \text {-value }\end{array}$ & Coeff & $\begin{array}{c}\text {-Stat. } \\
\text { value }\end{array}$ & Coeff & $\begin{array}{c}\text { T-Stat. } \\
\text { p-value }\end{array}$ & Coeff & $\begin{array}{c}\text { T-Stat. } \\
\text { p-value }\end{array}$ & Coeff & $\begin{array}{l}\text { T-Stat. } \\
p \text {-value }\end{array}$ & Coeff & $\begin{array}{c}\text { T-Stat. } \\
p \text {-value }\end{array}$ \\
\hline & Const. & $-0,1423$ & 0,45 & 0,2757 & $<0.01$ & 0,1979 & $<0.01$ & 0,1664 & $<0.01$ & 0,1092 & $<0.01$ & 0,2002 & $<0.01$ & 0,1120 & 0,04 \\
\hline & $H(1,1)$ & 0,0574 & $<0.01$ & 0,0495 & $<0.01$ & 0,0542 & $<0.01$ & 0,0520 & $<0.01$ & 0,0562 & $<0.01$ & 0,0503 & $<0.01$ & 0,0553 & $<0.01$ \\
\hline & $H(1,2)$ & 0,0641 & 0,01 & $-0,0252$ & 0,43 & 0,0534 & 0,01 & 0,0495 & 0,02 & $-0,0206$ & 0,44 & 0,0483 & 0,01 & 0,0520 & 0,01 \\
\hline & $H(2,2)$ & $-0,0016$ & 0,29 & 0,0018 & 0,23 & 0,0002 & 0,78 & 0,0005 & 0,65 & 0,0010 & 0,52 & 0,0002 & 0,89 & $-0,0005$ & 0,70 \\
\hline . & $\mathrm{RB}_{\mathrm{t}-1}$ & 0,1524 & $<0.01$ & 0,1552 & $<0.01$ & 0,1556 & $<0.01$ & 0,1551 & $<0.01$ & 0,1547 & $<0.01$ & 0,1527 & $<0.01$ & 0,1524 & $<0.01$ \\
\hline$\frac{\sigma}{\partial}$ & $\mathrm{RB}_{\mathrm{t}-2}$ & $-0,0353$ & 0,15 & $-0,0459$ & 0,05 & $-0,0398$ & 0,07 & $-0,0395$ & 0,08 & $-0,0491$ & 0,04 & $-0,0411$ & 0,07 & $-0,0367$ & 0,11 \\
\hline யே & $\mathrm{RB}_{\mathrm{t}-3}$ & 0,0291 & 0,20 & 0,0486 & 0,02 & 0,0325 & 0,11 & 0,0328 & 0,10 & 0,0464 & 0,04 & 0,0309 & 0,13 & 0,0303 & 0,17 \\
\hline 3 & $\mathrm{RB}_{\mathrm{t}-4}$ & 0,0014 & 0,95 & $-0,0124$ & 0,58 & 0,0045 & 0,85 & 0,0055 & 0,81 & $-0,0136$ & 0,63 & 0,0048 & 0,83 & 0,0043 & 0,85 \\
\hline$\ddot{q}$ & $\mathrm{RB}_{\mathrm{t}-5}$ & 0,0055 & 0,79 & 0,0023 & 0,92 & 0,0046 & 0,82 & 0,0064 & 0,75 & 0,0000 & 1,00 & 0,0062 & 0,76 & 0,0067 & 0,74 \\
\hline ฮ & $\mathrm{RS}_{\mathrm{t}-1}$ & $-0,0028$ & 0,58 & $-0,0027$ & 0,62 & $-0,0039$ & 0,41 & $-0,0035$ & 0,47 & $-0,0015$ & 0,77 & $-0,0032$ & 0,50 & $-0,0042$ & 0,38 \\
\hline$\sum_{0}^{\circ}$ & $\mathrm{RS}_{\mathrm{t}-2}$ & $-0,0047$ & 0,29 & $-0,0058$ & 0,20 & $-0,0040$ & 0,32 & $-0,0040$ & 0,32 & $-0,0054$ & 0,26 & $-0,0034$ & 0,48 & $-0,0038$ & 0,40 \\
\hline ¿ & $\mathrm{RS}_{\mathrm{t}-3}$ & 0,0022 & 0,64 & 0,0019 & 0,69 & 0,0014 & 0,75 & 0,0009 & 0,84 & 0,0022 & 0,68 & 0,0009 & 0,84 & 0,0019 & 0,68 \\
\hline & $\mathrm{RS}_{\mathrm{t}-4}$ & $-0,0007$ & 0,89 & $-0,0011$ & 0,82 & $-0,0020$ & 0,70 & $-0,0017$ & 0,73 & $-0,0007$ & 0,89 & $-0,0012$ & 0,81 & $-0,0022$ & 0,70 \\
\hline & $\mathrm{RS}_{\mathrm{t}-5}$ & $-0,0011$ & 0,83 & $-0,0033$ & 0,52 & $-0,0017$ & 0,73 & $-0,0015$ & 0,75 & $-0,0036$ & 0,48 & $-0,0014$ & 0,76 & $-0,0020$ & 0,66 \\
\hline & $\begin{array}{c}\text { Exog. } \\
\text { Indicator }_{\mathrm{t}-1}\end{array}$ & 0,0133 & 0,06 & $-0,1153$ & $<0.01$ & $-0,0300$ & 0,13 & $-1,0277$ & 0,15 & 0,0236 & $<0.01$ & $-0,0232$ & 0,07 & 0,0098 & 0,15 \\
\hline & Const. & 1,0362 & 0,06 & 0,2201 & 0,48 & 0,3413 & $<0.01$ & 0,2934 & 0,14 & 0,4577 & 0,03 & 0,1624 & 0,12 & 0,3845 & $<0.01$ \\
\hline & $H(1,1)$ & 0,0034 & 0,96 & 0,0508 & 0,51 & $-0,0068$ & 0,90 & 0,0096 & 0,87 & 0,0614 & 0,41 & $-0,0054$ & 0,92 & $-0,0102$ & 0,86 \\
\hline & $H(1,2)$ & 0,0186 & 0,26 & $-0,0026$ & 0,86 & 0,0109 & 0,01 & 0,0032 & 0,79 & 0,0076 & 0,63 & 0,0042 & 0,56 & 0,0144 & 0,19 \\
\hline & $\mathrm{H}(2,2)$ & $-0,0233$ & 0,44 & $-0,0152$ & 0,52 & $-0,0101$ & 0,48 & $-0,0123$ & 0,53 & $-0,0273$ & 0,37 & 0,0011 & 0,93 & $-0,0116$ & 0,52 \\
\hline . & $\mathrm{RB}_{\mathrm{t}-1}$ & 0,2903 & $<0.01$ & 0,2858 & $<0.01$ & 0,2799 & $<0.01$ & 0,2812 & $<0.01$ & 0,2926 & $<0.01$ & 0,2760 & $<0.01$ & 0,2850 & $<0.01$ \\
\hline$\frac{\text { ğ }}{3}$ & $\mathrm{RB}_{\mathrm{t}-2}$ & 0,0035 & 0,93 & 0,0286 & 0,49 & 0,0045 & 0,91 & 0,0069 & 0,86 & 0,0269 & 0,52 & 0,0046 & 0,91 & 0,0070 & 0,87 \\
\hline Шు & $\mathrm{RB}_{\mathrm{t}-3}$ & 0,0968 & 0,02 & 0,0861 & 0,05 & 0,0921 & 0,03 & 0,0867 & 0,03 & 0,0949 & 0,03 & 0,0916 & 0,03 & 0,0960 & 0,02 \\
\hline 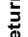 & $\mathrm{RB}_{\mathrm{t}-4}$ & 0,0006 & 0,99 & 0,0118 & 0,78 & 0,0084 & 0,85 & 0,0074 & 0,86 & 0,0069 & 0,87 & 0,0079 & 0,86 & 0,0046 & 0,92 \\
\hline$\ddot{q}$ & $\mathrm{RB}_{\mathrm{t}-5}$ & 0,1083 & 0,01 & 0,1222 & 0,01 & 0,1102 & 0,01 & 0,1071 & 0,01 & 0,1176 & 0,01 & 0,1122 & 0,01 & 0,1091 & 0,01 \\
\hline ब్ & $\mathrm{RS}_{\mathrm{t}-1}$ & 0,2370 & $<0.01$ & 0,2465 & $<0.01$ & 0,2372 & $<0.01$ & 0,2383 & $<0.01$ & 0,2425 & $<0.01$ & 0,2392 & $<0.01$ & 0,2383 & $<0.01$ \\
\hline$\sum_{\Sigma}^{\Sigma}$ & $\mathrm{RS}_{\mathrm{t}-2}$ & $-0,0491$ & 0,03 & $-0,0616$ & $<0.01$ & $-0,0459$ & 0,02 & $-0,0453$ & 0,02 & $-0,0656$ & 0,00 & $-0,0469$ & 0,03 & $-0,0474$ & 0,02 \\
\hline 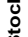 & $\mathrm{RS}_{\mathrm{t}-3}$ & $-0,0035$ & 0,88 & $-0,0023$ & 0,92 & $-0,0077$ & 0,72 & $-0,0078$ & 0,72 & 0,0014 & 0,95 & $-0,0072$ & 0,75 & $-0,0043$ & 0,85 \\
\hline & $\mathrm{RS}_{\mathrm{t}-4}$ & 0,0277 & 0,16 & 0,0200 & 0,32 & 0,0273 & 0,16 & 0,0275 & 0,17 & 0,0185 & 0,40 & 0,0287 & 0,15 & 0,0293 & 0,15 \\
\hline & $\mathrm{RS}_{\mathrm{t}-5}$ & 0,0759 & $<0.01$ & 0,0843 & $<0.01$ & 0,0744 & $<0.01$ & 0,0754 & $<0.01$ & 0,0829 & $<0.01$ & 0,0772 & $<0.01$ & 0,0768 & $<0.01$ \\
\hline & $\begin{array}{c}\text { Exog. } \\
\text { Indicator }_{\mathrm{t}-1}\end{array}$ & $-0,0368$ & 0,16 & 0,1595 & 0,43 & $-0,2315$ & 0,02 & $-1,7943$ & 0,43 & $-0,0806$ & 0,18 & 0,3670 & $<0.01$ & $-0,0302$ & 0,09 \\
\hline & $c_{11}$ & 1,1662 & $<0.01$ & $-0,0675$ & 0,14 & 0,0924 & $<0.01$ & 0,0975 & $<0.01$ & $-0,1069$ & $<0.01$ & 0,1148 & $<0.01$ & 0,5317 & $<0.01$ \\
\hline & $c_{21}$ & $-0,6100$ & 0,32 & 1,0126 & $<0.01$ & 0,1709 & 0,42 & 0,4097 & 0,11 & 0,7394 & $<0.01$ & 0,1927 & 0,26 & $-0,0399$ & 0,82 \\
\hline$\tilde{c}_{0}^{n}$ & $c_{22}$ & 0,0423 & 0,88 & 0,0000 & 1,00 & 0,8825 & $<0.01$ & 0,9695 & $<0.01$ & 0,0000 & 1,00 & 0,8866 & $<0.01$ & 0,7275 & $<0.01$ \\
\hline تِ & $\alpha_{11}$ & 0,3649 & $<0.01$ & 0,3770 & $<0.01$ & 0,3634 & $<0.01$ & 0,3715 & $<0.01$ & 0,3670 & $<0.01$ & 0,3825 & $<0.01$ & 0,3720 & $<0.01$ \\
\hline כु & $\alpha_{12}$ & $-0,0014$ & 0,98 & $-0,0011$ & 0,98 & 0,0197 & 0,65 & 0,0170 & 0,70 & $-0,0262$ & 0,64 & 0,0155 & 0,73 & 0,0118 & 0,81 \\
\hline ¿ & $\alpha_{21}$ & 0,0116 & 0,10 & $-0,0016$ & 0,84 & 0,0123 & 0,01 & 0,0115 & 0,05 & $-0,0003$ & 0,97 & 0,0114 & 0,01 & 0,0110 & $<0.01$ \\
\hline$\stackrel{\frac{5}{\sigma}}{\frac{\pi}{2}}$ & $\alpha_{22}$ & 0,2685 & $<0.01$ & 0,2221 & $<0.01$ & 0,2659 & $<0.01$ & 0,2626 & $<0.01$ & 0,2301 & $<0.01$ & 0,2653 & $<0.01$ & 0,2738 & $<0.01$ \\
\hline$\sum_{0}^{\frac{10}{0}}$ & $\beta_{11}$ & 0,9289 & $<0.01$ & 0,9360 & $<0.01$ & 0,9381 & $<0.01$ & 0,9352 & $<0.01$ & 0,9388 & $<0.01$ & 0,9310 & $<0.01$ & 0,9296 & $<0.01$ \\
\hline 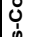 & $\beta_{12}$ & 0,0170 & 0,49 & 0,0766 & 0,53 & 0,0005 & 0,97 & 0,0009 & 0,95 & 0,0888 & 0,45 & 0,0016 & 0,91 & 0,0064 & 0,68 \\
\hline$\stackrel{8}{0}$ & $\beta_{21}$ & $-0,0025$ & 0,14 & $-0,0320$ & 0,03 & $-0,0047$ & 0,05 & $-0,0046$ & 0,04 & $-0,0322$ & 0,02 & $-0,0042$ & 0,06 & $-0,0028$ & 0,03 \\
\hline$\frac{5}{6}$ & $\beta_{22}$ & 0,9216 & $<0.01$ & $-0,9523$ & $<0.01$ & 0,9339 & $<0.01$ & 0,9334 & $<0.01$ & $-0,9445$ & $<0.01$ & 0,9364 & $<0.01$ & 0,9239 & $<0.01$ \\
\hline > & $\mathrm{K}_{11}$ & $-0,0421$ & $<0.01$ & $-0,0174$ & 0,71 & $-0,0010$ & 0,97 & 0,0747 & 0,95 & 0,0083 & 0,37 & $-0,0224$ & 0,29 & $-0,0601$ & $<0.01$ \\
\hline & $\mathrm{K}_{12}$ & 0,0240 & 0,35 & $-0,2340$ & 0,11 & 0,2472 & 0,02 & 6,8416 & 0,19 & 0,0632 & 0,02 & 0,1028 & 0,42 & 0,0257 & 0,18 \\
\hline & $\mathrm{K}_{22}$ & 0,0409 & 0,01 & 0,0000 & 1,00 & $-0,0311$ & 0,79 & 8,4569 & 0,01 & 0,0000 & 1,00 & $-0,0382$ & 0,64 & 0,0376 & 0,05 \\
\hline & $\begin{array}{c}\text { T-Dist. } \\
\text { Parameter }\end{array}$ & 5,2743 & $<0.01$ & 5,0367 & $<0.01$ & 5,1226 & $<0.01$ & 5,1774 & $<0.01$ & 5,0603 & $<0.01$ & 5,0945 & $<0.01$ & 5,2119 & $<0.01$ \\
\hline & Usable Obs. & 1480 & & 1480 & & 1480 & & 1480 & & 1480 & & 1480 & & 1480 & \\
\hline & $\begin{array}{c}\text { Log } \\
\text { Likelihood } \\
\end{array}$ & $-6211,62$ & & $-6235,96$ & & $-6221,50$ & & $-6219,62$ & & $-6231,01$ & & $-6219,86$ & & $-6219,65$ & \\
\hline 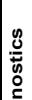 & & $\begin{array}{l}\text { Res. Bond } \\
\text { eqn. }\end{array}$ & $\begin{array}{c}\text { Res. } \\
\text { Stock } \\
\text { eqn. }\end{array}$ & $\begin{array}{l}\text { Res. Bond } \\
\text { eqn. }\end{array}$ & $\begin{array}{l}\text { Res. } \\
\text { Stock } \\
\text { eqn. }\end{array}$ & $\begin{array}{c}\text { Res. Bond } \\
\text { eqn. }\end{array}$ & Res. Stock eqn. & $\begin{array}{c}\text { Res. Bond } \\
\text { eqn. }\end{array}$ & $\begin{array}{c}\text { Res. Stock } \\
\text { eqn. }\end{array}$ & $\begin{array}{l}\text { Res. Bond } \\
\text { eqn. }\end{array}$ & $\begin{array}{l}\text { Res. Stock } \\
\text { eqn. }\end{array}$ & $\begin{array}{l}\text { Res. Bond } \\
\text { eqn. }\end{array}$ & $\begin{array}{l}\text { Res. } \\
\text { Stock } \\
\text { eqn. }\end{array}$ & $\begin{array}{c}\text { Res. Bond } \\
\text { eqn. }\end{array}$ & $\begin{array}{c}\text { Res. Stock } \\
\text { eqn. }\end{array}$ \\
\hline .5 & $\begin{array}{c}\text { Ljung-Box } \\
\mathrm{Q}(12) \\
\text { p-value }\end{array}$ & 0,49 & 0,70 & 0,5657 & 0,92 & 0,4221 & 0,86 & 0,4451 & 0,82 & 0,57 & 0,83 & 0,4513 & 0,84 & 0,5681 & 0,75 \\
\hline & $\begin{array}{l}\text { McLeod- } \\
\text { Li(12) } \\
\text { p-value }\end{array}$ & 0,44 & 0,15 & 0,6576 & 0,06 & 0,5702 & 0,13 & 0,5487 & 0,14 & 0,6946 & 0,07 & 0,7862 & 0,18 & 0,4724 & 0,11 \\
\hline & $\mathrm{ARCH}(12)$ & & & & & & & & & & & & & & \\
\hline & $\begin{array}{c}\text { Test } \\
\text { p-value }\end{array}$ & 0,51 & 0,23 & 0,706 & 0,10 & 0,628 & 0,18 & 0,603 & 0,19 & 0,746 & 0,14 & 0,817 & 0,24 & 0,541 & 0,17 \\
\hline
\end{tabular}

Notes: Bold numbers indicates statistical significance 
Focusing on the coefficients of the uncertainty news indicators, it appears that the effect exerted depends on the type of news. In particular, they reveal a direct positive effect on bond returns emanating from increased uncertainty concerning security markets news and a negative effect from uncertainty induced by government policy news. In a similar manner, stock market returns are positively affected by uncertainty induced by War news and negatively affected by intermediation news implied uncertainty. Worth mentioning is that for both stock and bond markets the aggregate index of NVIX does not indicate any significant impact. This result highlights the importance of disaggregating news implied uncertainty into different types and uncertainty generating sources. Let us now turn to the direct effects of news-implied uncertainty on variance equation of both bond and stock returns (see Variance-Covariance section of Table 3). As a general observation, an increase of the NVIX has a significant reduction on bond variability (as implied by the negative and statistically significant coefficient $\mathrm{k}_{1,1}$ ) and a significant rise on stock variability (as implied by the positive and statistically significant coefficient $\mathrm{k}_{2,2}$ ). The former result may be attributed to the last category, entitled as "unclassified news" when comparing the results across the different categories. While, the latter may be attributed to NATDIS news and unclassified news also. News implied uncertainty concerning intermediation policy and security markets bring about a significant increase in the correlation of the two markets (see coefficient $\mathrm{k}_{1,2}$ ) reducing any diversification benefits for portfolio managers. 
Table 4: Estimation results for the VAR-BEKK-GARCH(1,1)-in-mean model for UK data

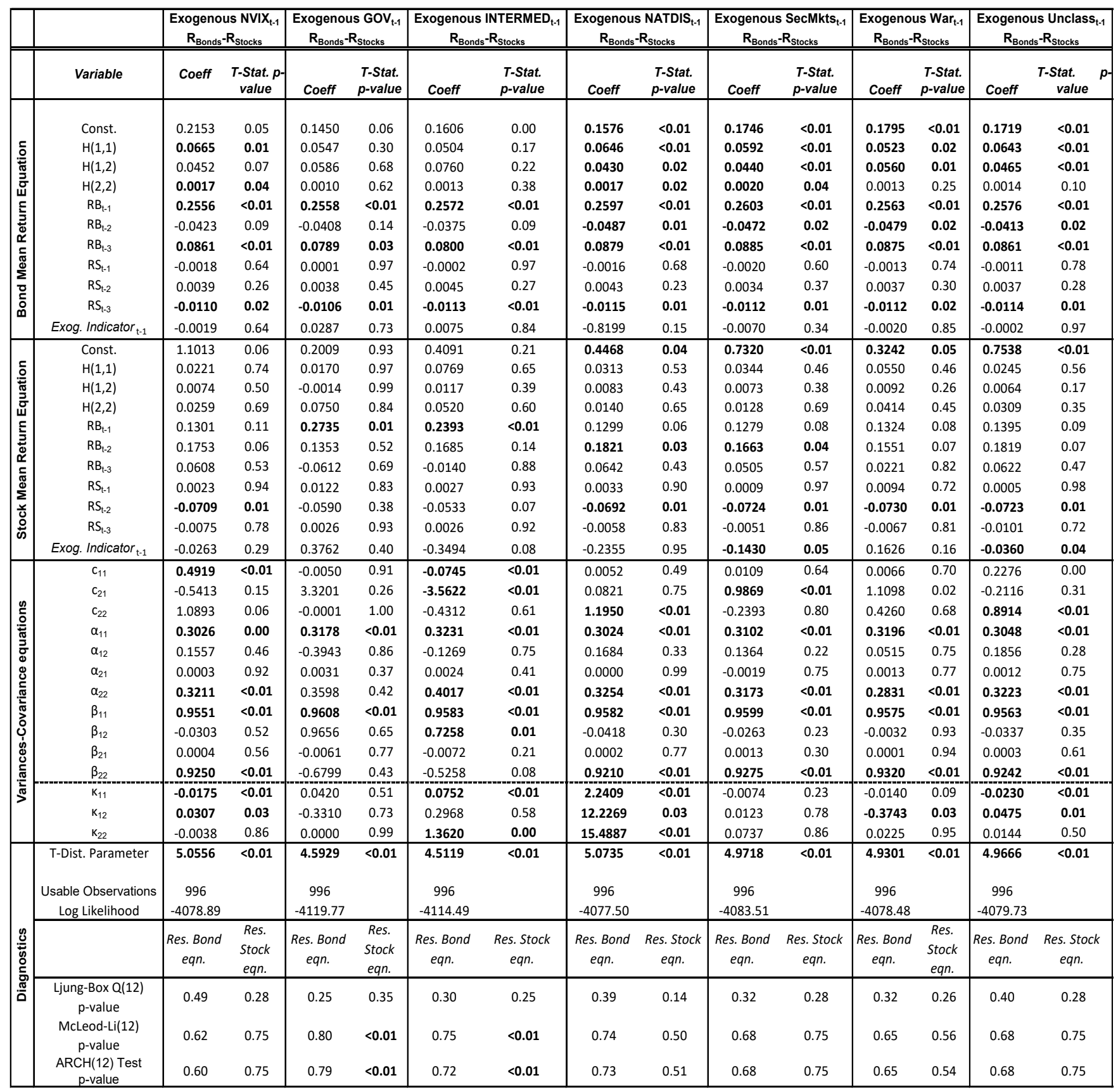

Notes: Bold numbers indicates statistical significance 
Let us now turn to the results in the case of the UK presented in Table 4. The positive riskreturn relationship is also present to a certain degree only for the bond market but in the cases of uncertainty news concerning government policy and intermediation this positive relationship disappears. Additionally, the increased variability on stock market has a significant positive effect on bond returns and this is mainly attributed to the NATDIS and SecMkts components of NVIX. Bond returns present a notable persistence as indicated by the statistical significance of its lagged values. Worth mentioning is the negative effect of stock returns present under a three period delay. Unlike the US case, stock returns have a positive impact after one period on bond returns, in only two cases: the uncertainty induced by government policy news and by intermediation policy news. Furthermore, the NATDIS and SecMkts components present a significant positive effect on stock returns in a two time-lag specification. When it comes to the direct effects of news-implied indicators on bond returns and in line with the US case, there are no significant results. Nevertheless, negative effects on stock returns can be observed because of security markets and unclassified factors-stemming uncertainty news. Just as in the case of the US result, the NVIX exerts a negative and statistically significant effect on bond volatility that is mainly attributed to the unclassified news factor. However, positive effects on bond volatility are based on the effects of the intermediation and NATDIS components. The same applies when examining the stock volatility. When examining the covariance effects of uncertainty news on the UK case, it can be argued that the positive sign of NVIX coefficient on the covariance equation may be attributed to the NATDIS and unclassified news components. Notably, the correlation between the two markets is significantly reduced over the war-invoked news. This latter result implies substantial diversification benefits between the two markets during war periods. If we turn to the other coefficients in the variance equations, it can be seen that both the stock and bond markets present 
a similar high volatility persistence (compare the $\beta_{11}$ to the $\beta_{22}$ coefficients). Furthermore, the $\alpha_{11}$ coefficients can in broad terms be characterised as being higher in magnitude in US case compared to UK. While the $\alpha_{22}$ coefficients are, lower in the US versus the UK markets. This implies that the impact of news on bond variability is higher in US compared to UK and the opposite for the impact of news on stock variability (compare in Tables 3 and 4 the magnitude of the $\alpha_{11}$ and $\alpha_{22}$ coefficients respectively).

Does NVIX has any incremental information not included in VIX for predicting stock and bond return moments and correlations?

A number of studies such as Connolly et al. (2005) argue that VIX significantly predicts stock-bond co-movement. In this part of the paper, we examine whether NVIX has any incremental information not included in VIX for predicting stock and bond return moments and correlations. Given that data availability for VIX begins in 1990s our data sample for this type of analysis is reduced from January 1990 to March 2016. By taking the difference of the variables in their logarithmic levels, we estimate again our BEKK_GARCH models for the case of US and UK markets. As can be seen in Table 5, the excess variability based on media press coverage has a positive effect on predicting stock market over the next period in US, but only bond market in the UK. In the US higher return is required for higher news-based uncertainty of the previous month, while in the UK a flight to safety is identified by the positive bond return reaction. What is common across the two markets and interesting is the negative and statistical significant coefficient k22. This finding implies that the overreaction of investors reflected on NVIX indicator is reducing the next month stock market volatility. Therefore, these behavioral aspects present a temporal character in the stock markets. Overall, the additional information of the NVIX in contrast to VIX index may be a valuable tool for investors and fund managers when constructing their asset 
allocation. However, as have been seen in terms of returns are interpreted differently between US and UK investors.

Table 5: Estimation results for the VAR-BEKK-GARCH(1,1)-in-mean model for NVIX versus VIX for both the UK and US data

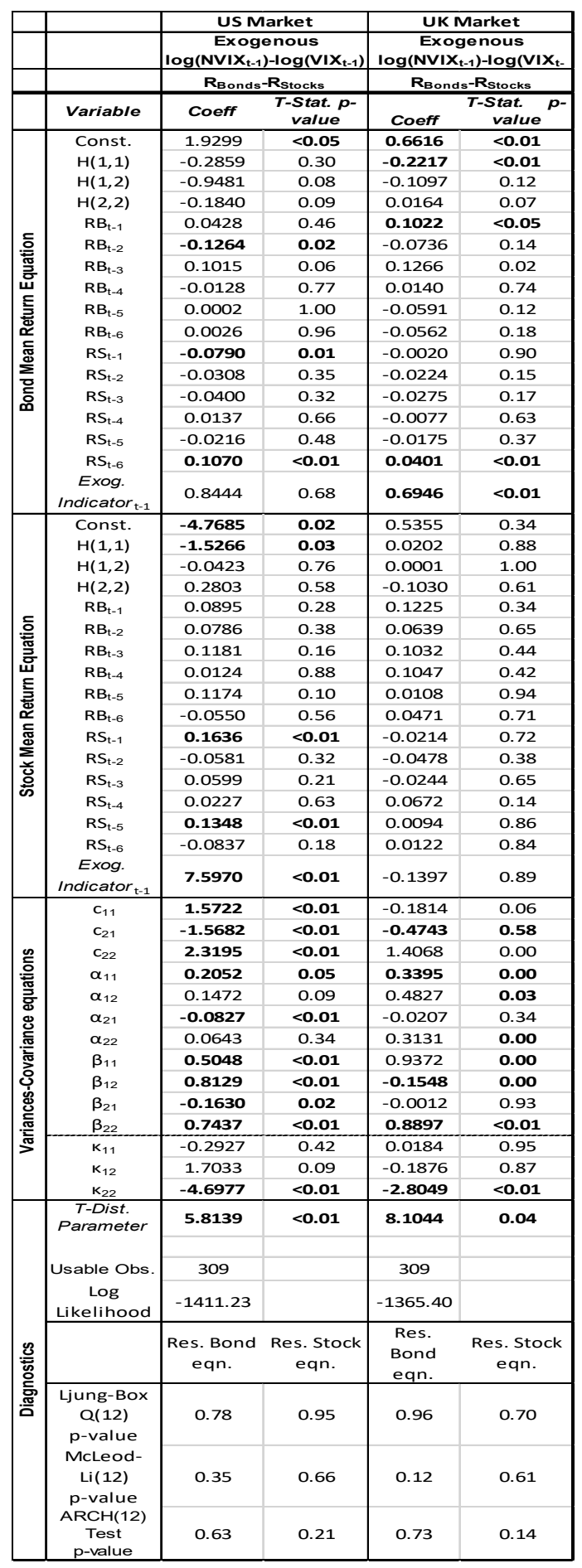




\section{Concluding Remarks}

The paper focused on the effects of news based uncertainty on the stock-bond covariance, their returns, and their variances. To this effect, the news implied volatility index - NVIX- was used. To allow for different effects that depend on the source of uncertainty, the index was also decomposed into its six sub-indices that account for uncertainty emanating from war and conflict, securities markets, natural disasters, government and intermediation policy as well as unclassified uncertainty (Manela and Moreira, 2017). Uncertainty news may trigger a capital movement from risky assets to more safe assets, i.e a flight-to-quality effect. Using VAR methodology and a multivariate GARCH-in-mean framework that allows the modelling of the variance with the covariance, we investigated the effect of uncertainty news on stock and bond returns and their variances. Moreover, their time varying correlation was also examined in this framework. In a nutshell, our findings indicate a positive risk return relationship for US bond market and to a lesser extend in the case of the British bond market. Stock returns were found to influence negatively bond market returns in both countries and, interestingly, the effect is unidirectional only in the case of the USA. Bond returns are positively influenced by the increased uncertainty concerning security markets news and negatively influenced from uncertainty induced by government policy news. No effect is traced on UK bond returns. When it comes to the effects exerted by NVIX and its constituent components the findings are mixed. This should not come as a surprise since different news can and do affect in different ways the bond and stock markets. The results reported herein seem to corroborate this intuitive expectation. A more prominent result is provoked on bond and stock variability by the uncertainty news in case of the US. More specifically, the negative effect of NVIX on bond variability is attributed to unclassified news while the positive effect on stock variability is also laid on unclassified news and NATDIS news. Albeit appreciably feebler, 
this result applies in the UK but the sign of the effect is more dependent on the type of uncertainty news. Bond returns are positively influenced by the increased uncertainty concerning security markets news and negatively influenced from uncertainty induced by government policy news. No effect is traced on the UK bond returns. Correlation between the two markets is found to be increased significantly over specific type of uncertainty news for both the US and the UK. In case of the latter, however, uncertainty news about war trigger diversification benefits as indicated by the appearance of a negative correlation between stock and bond market. Finally, the overreaction of investors incorporated on NVIX index highlights in a more clear manner any flight to quality effects during a long time-period studied, and have significant implications for the asset management of a fund. Fund managers and stock-bond holders may use the NVIX indicator and its components as signals for next period return and variability in the relevant markets, and identify any sift from one market to the other. However, investors in the US and the UK markets present a degree of heterogeneity in their responses. 


\section{REFERENCES}

Andersson, M., Krylova, E., Vahamaa, S. 2008. Why does the correlation between stock and bond returns vary over time? Applied Financial Economics 18, 139-151

Antonakakis, N., Chatziantoniou, I., Filis, G., 2014. Dynamic spillovers of oil price shocks and economic policy uncertainty. Energy Econ. 44, 433-447.

Apergis, N., M. Bonato, R. Gupta and C. Kyei. 2017. Does geopolitical risks predict stock returns and volatility of leading defense companies? Evidence from a nonparametric approach. Defence and Peace Economics doi.org/10.1080/10242694.2017.1292097

Asgharian, H., Christiansen, C., Hou, A.J., 2015. Effects of macroeconomic uncertainty on the stock and bond markets, Finance Research Letters 13, 10-16.

Aslam, F. and H-G. Kang. 2015. How different terrorist attacks affect stock markets, Defence and Peace Economics 26(6), 634-648

Aslanidis, N., Christiansen, C. 2012. Smooth transition patterns in the realized stock-bond Correlation. Journal of Empirical Finance, 19, 454-464.

Aslanidis, N., Christiansen, C. 2014. Quantiles of the realized stock-bond correlation and links to the macroeconomy. Journal of Empirical Finance, 28, 321-331.

Baele, L., G. Bekaert and K. Inghelbrecht 2010 The determinants of stock and bond return comovements, Review of Financial Studies 23(6), 2374-2428

Baur, D. and B. Lucey. 2009. Flights and contagion. An empirical analysis of stock-bond correlations. Journal of Financial Stability 5: 339-352.

Bauwens, L., S. Laurent and J. Rombouts. 2006. Multivariate GARCH models: a survey. Journal of Applied Econometrics 21:79-109.

Bonga-Bonga, L. 2017. Uncovering equity market contagion among BRICS countries: An application of the multivariate GARCH model. The Quarterly Review of Economics and Finance, doi.org/10.1016/j.qref.2017.04.009

Boudoukh, J., Feldman, R., Kogan, S.,\& Richardson, M. 2013. Which news moves stock prices? A textual analysis (NBERWorking Paper No. 18725).

Brune, A., T. Hens, O. Rieger and M. Wang 2015. The war puzzle: contradictory effects of international conflicts on stock markets, International Review of Economics 62:1-21

Campbell, J.Y., Ammer, J. 1993. What moves the stock and bond markets? A variance decomposition for long-term asset returns. Journal of Finance, 48, 3-37. 
Chang, C. L., and Hsueh, P. L. 2013. An investigation of the flight-to-quality effect: Evidence from Asia-Pacific countries. Emerging Markets Finance and Trade 49, 53-69.

Chen, H., De, P., Hu, Y., \& Hwang, B. H. (2014). Wisdom of crowds: The value of stock opinions transmitted through social media. The Review of Financial Studies, 27(5), 1367-1403.

Connolly, R., Stivers C., Sun L. 2005. Stock market uncertainty and the stock-bond return relation. Journal of Financial and Quantitative Analysis 40, 161-194

Connolly, R., Stivers C., Sun L. 2007. Commonality in the time-variation of stock-stock and stockbond return comovements. Journal of Financial Markets 40, 192-218Conrad, C., Loch, K., Rittler, D., 2014. On the macroeconomic determinants of long-term volatilities and correlations in U.S. stock and crude oil markets Journal of Empirical Finance, 29, 26-40.

d'Addona, S., Kind, A.H. 2006. International stock-bond correlations in a simple affine asset pricing model. Journal of Banking \& Finance, 30, 2747-2765

Dajcman, S. 2012. Comovement between stock and bond markets and the flight-to-quality during financial market turmoil- A case of the Eurozone countries most affected by sovereign debt crisis of 2010-2011, Applied Economics Letters 19, 1655-1662.

Dimic, N., Kiviaho, J., Pijak, V., Äijö, J., 2016. Impact of financial market uncertainty and macroeconomic factors on stock-bond correlation in emerging markets. Research in International Business and Finance 36, 41-51.

Dougal, C., Engelberg, J., Garcia, D., \& Parsons, C. A. (2012). Journalists and the stock market. The Review of Financial Studies, 25(3), 639-679.

Durand, R. B., Junker, M., and Szimayer, A. 2010. The flight-to-quality effect: A copula-based analysis, Accounting and Finance 50, 281-299.

Engle, R. F., Lilien, D. M., \& Robins, R. P. 1987. Estimating time varying risk premia in the term structure: The ARCH-M model. Econometrica: Journal of the Econometric Society, 391407.

Engle, R.F., Kroner, K., 1995. Multivariate simultaneous GARCH. Econometric Theory, 11, 122 150.

Fang, L., \& Peress, J. 2009. Media coverage and the cross-section of stock returns. The Journal of Finance, 64(5), 2023-2052.

Guidolin, M., La Ferrara, E., 2010. The economic effects of violent conflict: evidence from asset market reactions. Journal of Peace Research, 47, 671-684 
Gulko, L. 2002. Decoupling. Journal of Portfolio Management 28, 59-66

Hassan, M. K., A. Paltrinieri, A. Dreassi, S. Miani and A. Sclip. 2017. The determinants of comovement dynamics between sukuk and conventional bonds The Quarterly Review of Economics and Finance, doi.org/10.1016/j.qref.2017.09.003

Ilmanen, A. 2003. Stock-bond correlations. Journal of Fixed Income 13, 55-66

Jammazi, R., A. Tiwari, R. Ferrer, P. Moya. 2015. Time-varying dependence between stock and government bond returns: International evidence with dynamic copulas, North American Journal of Economics and Finance 33, 74-93

Kaplanski, G., Levy, H., 2010. Sentiment and stock prices: The case of aviation disasters. Journal of Financial Economics 95, 174-201.

Kim, S., Moshirian F., Wu E. 2006. Evolution of international stock and bond market integration: Influence of the European Monetary Union. Journal of Banking and Finance 30, 1507-1534

Kollias, C., S. Papadamou and V. Arvanitis. 2013. Does terrorism affect the stock-bond covariance? Evidence from European Countries, Southern Economic Journal 79(4), 832848

Li, L. 2002. Correlation of stock and bond returns. Working Paper, Yale University

Li, L. 2004. Macroeconomic factors and the correlation of stock and bond returns. Proceeding of the 2004 American Finance Association Meeting

Li, X., Zou, L. 2008. How do policy and information shocks impact co-movements of China's Tbond and stock markets? Journal of Banking and Finance 32, 347-359

Longin, F., Solnik, B. 1995. Is the correlation in international equity returns constant: 1960-1990? Journal of International Money and Finance 14, 3-26

Macchiarelli, C. 2014. Bond market co-movements, expected inflation and the GBP-USD equilibrium real exchange rate. The Quarterly Review of Economics and Finance, 54(2), $242-256$

Manela, A. and Moreira, A. 2017. News implied volatility and disaster concerns. Journal of Financial Economics, 123(1), 137-162.

Newey, W. and K. West. 1987. A simple positive semi-definite, heteroscedasticity and autocorrelation consistent covariance matrix. Econometrica 55:703-08. 
Nikkinen, J., Omran, M., Sahlstrom, P., Aijo, J., 2008. Stock returns and volatility following the September 11 attacks: evidence from 53 equity markets. International Review of Financial Analysis, 17, 27-46

Ohmi H. and T. Okimoto. 2016 Trends in stock-bond correlations, Applied Economics 48(6): 536552

Penga G., Huiming, Z. Wanhaic, Y. 2018. Asymmetric dependence between economic policy uncertainty and stock market returns in G7 and BRIC: A quantile regression approach. Finance Research Letters, forthcoming.

Rankin, E., Shah Idil, M. 2014. A century of stock-bond correlations. Reserve Bank of Australia Bulletin, September, 67-74.

Sakemoto, R. 2018. Comovement between equity and bond markets. International Review of Economics and Finance, 53, 25-38. 613

Schneider, G., Troeger, V., 2006. War and the world economy, Stock market reactions to international conflicts. Journal of Conflict Resolution 50, 623-645.

Shiller, R.J., Beltratti, A.E. 1992. Stock prices and bond yields: Can their comovements be explained in terms of present value models? Journal of Monetary Economics, 30, 25-46.

Skintzi, V. 2017 Determinants of stock-bond market comovement in the Eurozone under model uncertainty. MPRA Paper No. 78278

Su, Z., Fang, T., \& Yin, L. 2017. The role of news-based implied volatility among US financial markets. Economics Letters, 157, 24-27.

Tetlock, P. C. 2007. Giving content to investor sentiment: The role of media in the stock market. The Journal of Finance, 62(3), 1139-1168.

Tetlock, P. C., Saar-Tsechansky, M., \& Macskassy, S. 2008. More than words: Quantifying language to measure firms' fundamentals. The Journal of Finance, 63(3), 1437-1467.

Thomadakis, A. 2012 Contagion or flight-to-quality phenomena in stock and bond returns DP 06/12 Department of Economics University of Surrey

Yang J., Zhou Y. and Wang Z. 2009. The stock-bond correlation and macroeconomic conditions: one and a half centuries of evidence. Journal of Banking and Finance 33(4), 670-680.

Yang, J., Y. Zhou, and Z. Wang. 2010. Conditional co-skewness in stock and bond markets: Time series evidence, Management Science 56, 2031-2049. 